\title{
THE CREATION OF VISITOR SATISFACTION THROUGH QUALITY OF EXPERIENCE IN THE GASTRONOMIC TOURISM AT THE CITY OF BANDUNG, INDONESIA
}

\author{
Vany Octaviany, Ersy Ervina. \\ Telkom University \\ vany@tass.telkomuniversity.ac.id, ersy@tass.telkomuniversity.ac.id
}

\begin{abstract}
Visitors need something more than just a delicious meal with a good appearance to be satisfied. They need something they can easily remember when they deal with a gastronomic tourism in the city of Bandung. Something they remember is called experience. Unforgettable experience will produce an unforgettable memory, making the Visitors recall their past experience. Quality of experience can affect visitor satisfaction through the impression given by the gastronomic product attributes. But today, the quality of experience is considered to be unable to create satisfaction as sustainable strategy, because usually the gastronomic tourism managers prefer improving 'taste' to creating a good impression in the minds of Visitors. A good impression is able to lead the visitors to return, even invite others to come along to the city of Bandung. Therefore, this study was aimed at examining the creation of visitor satisfaction through the quality of experience at a gastronomic tourism in Bandung. This study used a quantitative method. The data analysis techniques included regression analysis. The results showed that the quality of experience is able to create a visitor satisfaction by $60.1 \%$. The highest score is given on the impression perceived during the visit to the gastronomic tourism area.
\end{abstract}

Keywords: Quality of Experience, Visitor Satisfaction, Gastronomic Tourism, Bandung

\section{Introduction}

Bandung is currently showing significant progress in the development of the leading city as urban tourism. Visitor attraction in the city of Bandung can be viewed from the supporting elements. The supporting elements are the primary elements and secondary elements. The primary elements consist of landscape, gallery or museum, cultural activities, business / sport / history / heritage, and special pilot-project area. Meanwhile, the secondary elements include shopping facilities, markets, souvenirs, entertainment, restaurants and urban functions (education, health, fabrication). The second elements deserve a great tourism potential, as a form of secondary elements, culinary tourism become as one of the attraction of visitors visiting the city of Bandung.

Based on data from the Department of Culture and Tourism of Bandung, visitor arrivals show a significant increase every year. In 2014, the total visitors 
reach $34,677,904$, increasing by $16.4 \%$ from the previous year. Such an increase can have a positive impact on the development of tourism in Bandung. This is certainly not separated from attractions existing at the city of Bandung itself. One of the attractions is the gastronomic tourism area.

Gastronomic tourism refers to trips made to destinations where the local food and beverages involving visitors to taste, prepare, experiment, research, find, understanding and write about food and beverages. Gastronomic tourism, as a basic part of culinary tourism, is currently becoming one of the main motivation for visitors to visit a new destination. Gastronomic tourism offered by an area is a manifestation of its culture. Local food market is recognized as an important element of the cultural experience and tourism of an area, thus the local identity is reinforced due to the food products. Kivela (2006) in Londoño (2012:2) claims that gastronomic tourism is growing, that a lot of visitors make a trip only to discover the typical culinary offerings of a certain area. Gastronomic tourism also becomes a way for visitors to gain knowledge about the wealth of a destination through the food they find, and a new way to socialize with the environment.

The high interest of visitors in the gastronomic tourism is expected to provide satisfaction after visitors visit to the city of Bandung. The quality of satisfaction is an expression of the visitor feelings after doing a comparison between the products and services provided gastronomic tourism of Bandung and their expectations. When being satisfied, they will re-visit the city of Bandung and recommend the gastronomic tourism products to others. In other words, when visitors are satisfied with gastronomic tourism products in Bandung, there will be a long-term effect, i.e. repeat their visits and arrival of new visitors.

Gastronomic tourism is closely related to culinary tourism. It cannot be denied that one aspect of experience quality is about how the gastronomic products they receive. That is related to the taste of the food, then the texture, temperature and appearance. These aspects are included in the category of an assessment of the quality of the food. However, awareness to create quality food must be owned by any food business managers, so it can be ascertained that the stakeholders involved in the gastronomic tourism of Bandung have their own standards to ensure good quality gastronomical products.

According to Crompton and Love (1995:12) in Wu, Li, and Li (2014:5), quality of experience is defined as a personal reaction and feeling resulting from participation in tourism activities as well as the affective or emotional condition of tourist in terms of psychology. The quality of the experience does not only involve the attributes given by the supplier, but the chances of attributes that can be taken home by visitors. Based on the above background, this study explored more about the quality of visitor experience in creating satisfaction for visitors in the city of Bandung. In specific, this study was aimed to:

1. identify and analyze the visitor satisfaction with the gastronomic tourism in Bandung.

2. identify and analyze the quality of the tourist experience in the most dominant factor in the behavior of visitors in gastronomic tourism in Bandung.

3. identify and analyze the level of effect the quality of experience on the quality of the gastronomic tourism experience 


\section{Literature Review}

\section{Gastronomic Tourism}

Gastronomic tourism is the main factor that motivates a person to visit a specific destination. According to Pullphothong and Sopha (2012:3), gastronomic tourism is a participative style in seeking vacation experiences, to meet the interest in food and beverages and contribute to the development of personal and social status. According to the International Culinary Tourism Association (ICTA), culinary tourism is defined as tourism activities to enjoy food and beverages. Therefore, gastronomic tourism refers to trips undertaken for the purpose of enjoying food and beverages as the primary motivating factor for travel. Gastronomy is also stated as an art or a quest of good eating quality, including in the selection, preparation, service and enjoyment of food and variety culture or style of cuisine (Inskeep, 1991).

Gastronomic tourism can increase the resale value of an area and develop the potential of the region with the increased interest of visitors to visit the area. The benefits of gastronomic tourism development, according to Anton Clave and Knafou (2012: 3), include:

1. Globalization as the standardization of taste, not only in fast food, but also how the food is locally acceptable by world visitors.

2. Standardization of taste as a strategy of mediation between the local gastronomic culture and cultural diversity of gastronomic visitors.

3. The difference between the local gastronomic products and gastronomic products is connected in the world of value chain, which is related in the dimension of the world of wealth of culinary products;

4. The diversity of(global / local) gastronomic products can have an impact on regional development

5. Gastronomic tourism is related to the identity of the authentic area

\section{Quality of Experience}

According Stamboulis and Skayannis (2003) in Chang, Backman, and Huang (2014: 405) during the trip tourism experience pertaining to visit, see, learn, and enjoy a different lifestyle. Meanwhile, According to Smith (2006: 4) reveals that visitors experience includes, aspects of people met, places they visit, the accommodation in which they live, also participate in the activities which make a memorable tour. And for providers of tourism activities, it integrates all aspects, the visitor experience is included in trip planning, pre-trip, basic services were improved, the follow-up program post. To satisfy the desire of visitors to gain more experience and satisfaction with service providers need to pay attention to Quality of Experience, This is reinforced in the study of Chen and Chen (2010: 30) Quality of Experience is the result generated from consumer participation in tourism activities. Crompton and Love (1995) in $\mathrm{Wu}, \mathrm{Li}$, and $\mathrm{Li}$ (2014: 5) The quality of the experience is not only involves the attributes given by the supplier, but the chances of attributes that can be taken home by visitors.

According to Chen and Chen (2010, p. 30) states that there are several dimensions to measure the quality of experience including:

1. Hedonics is associated with the affective responses such as excitement, enjoyment and memorability. 
2. Peace of mind is concerned about the need for both physical and psychological safety and comfort.

3. Involvement Refers to the desire to have choice and control in the service offering, and the demand to be educated, informed and imbued with a sense of mutual cooperation.

4. Recognition is linked to feeling important and confident while consumers themselves are being taken seriously.

In this study, the dimensions of the quality to be developed are Hedonics, Peace of mind, Involvement and Recognition, because these are considered most appropriate to conditions on the field.

\section{Customer satisfaction}

Satisfaction can be interpreted as an effort to fulfill something or make something adequate. According to Lovelock in Tjiptono (2011: 58), Satisfaction is the attitude assessment that follows the consumption experience. Customers will be quite satisfied with the performance during the performance are said to fall into the tolerance zone which is above the level of adequate services. Meanwhile, according to Solomon in Tjiptono (2011: 394), satisfaction or dissatisfaction is associated with a reaction to how well the achievement of the performance of the product or service.

Lovelock and Wirtz (2011: 74) states that "Satisfaction is an attitude like a judgment following a consumption experience". Satisfaction is an attitude that is decided on the basis of experience gained.

Kotler and Keller (2012: 128) defines a person's satisfaction as the feeling of pleasure or disappointment resulting from comparing the performance of the product in terms of perception and expectation. Kotler and Keller (2012: 128) states that the satisfaction is gained from comparing the perception and expectation of a product.

\section{Research Framework}

Based on the description of literature review, this study made a framework of research in order to facilitate the research process. The framework is presented in Figure 1 as follows. 
Figure 1

Research Paradigm

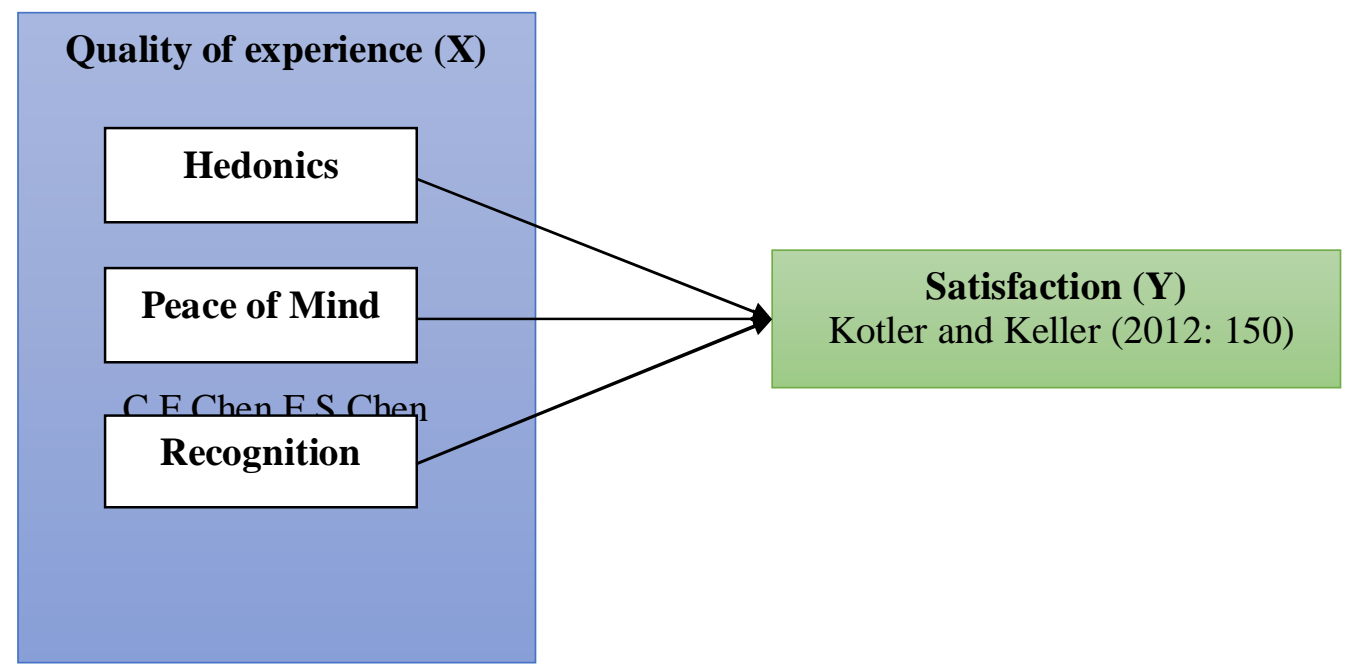

After performing a search for the related research, it is known that this study model has not been done before. Thus, this study has high originality. The state of the art thing of this study is to see how the quality of experience can create visitor satisfaction in Bandung gastronomic tourism.

\section{Methodology}

\section{Research Object}

This study analyzed the effect of the quality of experience on the visitor satisfaction. Variables consisted of independent and dependent variables. The independent variables are Quality of Experience (X), which consists of three subvariables, Hedonics $\left(\mathrm{X}_{1)}\right.$, Peace of Mind $\left(\mathrm{X}_{2}\right)$, and Recognition $\left(\mathrm{X}_{3}\right)$. This study was conducted at three restaurants serving Bandung gastronomic products, which represent the gastronomic visitor area in Bandung, including Jl. Riau, Jl. Setiabudhi and Gasibu. This research was done in less than one year, then the method used was cross sectional method.

\section{Research method}

This research was a descriptive and verificative research. The method used was explanatory survey. In this study, population included the number of visitor arrivals in 2014 , i.e. $34,677,904$ while the sample was a total of 100 people. With a sampling technique using systematic random sampling. Techniques of data collection were interviews, questionnaire, observation and document review. The measuring instruments used to make questions on the questionnaire was Likert scale. Technical analysis of the data used Path Analysis.

\section{Results and Discussion}

Based on the results of data processing on 100 questionnaires distributed to visitors who visit Bandung Gastronomic Tourism regarding perceived quality 
of experience, it can be seen that the highest score is on the quality dimension of experience is reflected in the following table:

\section{Table 1}

\section{Recapitulation of Visitor Response on the Experience Quality of Gastronomic Tourism}

\begin{tabular}{|l|l|l|l|}
\hline o. & Sub Variables & Score & Average \\
\hline & Hedonics & 796 & 398 \\
\hline & Peace of Mind & 1088 & 362.6 \\
\hline & Recognition & 746 & 373 \\
\hline \multicolumn{2}{|c|}{ Total } & $\mathbf{2 6 3 0}$ & $\mathbf{1 1 3 3 . 6}$ \\
\hline
\end{tabular}

Source: Data Processing, January 2016

Table 1 shows that Hedonics get the highest score as a dimension of quality of experience. Hedonics is associated with affective responses such as joy, pleasure and memories of the past. According to Chen and Chen (2010:30), hedonics is a behavior that is formed on the basis of feelings, interests, attitudes, emotions, and the value of a person when responding to an event. Visitors feel a sense of joy, happy and impressed after visiting Bandung Gastronomic Tourism. It is because the gastronomic products are known to have good quality, high innovation, inexpensive price and uniqueness that cannot be found elsewhere. Indicator of hedonics which get the highest response is impressed by the experience while enjoying the gastronomic products. Gastronomic Products are cultural products which have a high value for visitors. As claimed by (Kemmer, 2000), gastronomic tourism is regarded as a different way for visitors to perceive unique culinary products based on culture not only on taste, but refer to Foodways or as an act or behavior involved in the preparation, presentation and consumption the food by individuals and communities.

Based on the results of survey responses in the satisfaction of the Gatronomic Tourism, the recapitulation of satisfaction is as follows:

Table 2

Recapitulation of Visitor Response to the Satisfaction in the Gastronomic Tourism

\begin{tabular}{|l|c|c|c|}
\hline o. & Sub Variables & Score & Averag \\
\hline & Quality Foods & $\mathbf{2 7 6 2}$ & $\mathbf{4 0 0}$ \\
\hline $\begin{array}{c}\text { Product Attributes } \\
\text { gastronomy }\end{array}$ & 753 & 376 \\
\hline Price & 400 & 395 \\
\hline Total & $\mathbf{3 9 1 5}$ & $\mathbf{1 1 7 1}$ \\
\hline
\end{tabular}

Source: data processing, January 2016

Table 2 shows that visitor response to the quality of experience is high, 
with a total score (the highest) of 1171 . The highest response is on the suitability between hope and reality and expectation, i.e. taste, portion, innovation, presentation, texture, temperature and hygiene. Bandung gastronomic products are known to have a bad taste. In addition to delicious, Bandung gastronomic products are served with a generous portion, texture and temperature according to the standard. Innovation and manner of presentation are interesting for visitors.

The hypothesis to be tested in this study is the effect of quality of experience on the satisfaction of visitors in the gastronomic tourism in Bandung. To prove the hypothesis, test of effect between variables is done using SPSS 20.0

\section{Classic assumption test}

\section{Results of Assumption Normality Test}

Data distribution is not normal, because there are extremes in the data. To detect it is by using a histogram of residual regression that has been standardized. Figure 3 shows the histogram of visitor satisfaction.

\section{Figure 3}

\section{Visitor Satisfaction Histogram}

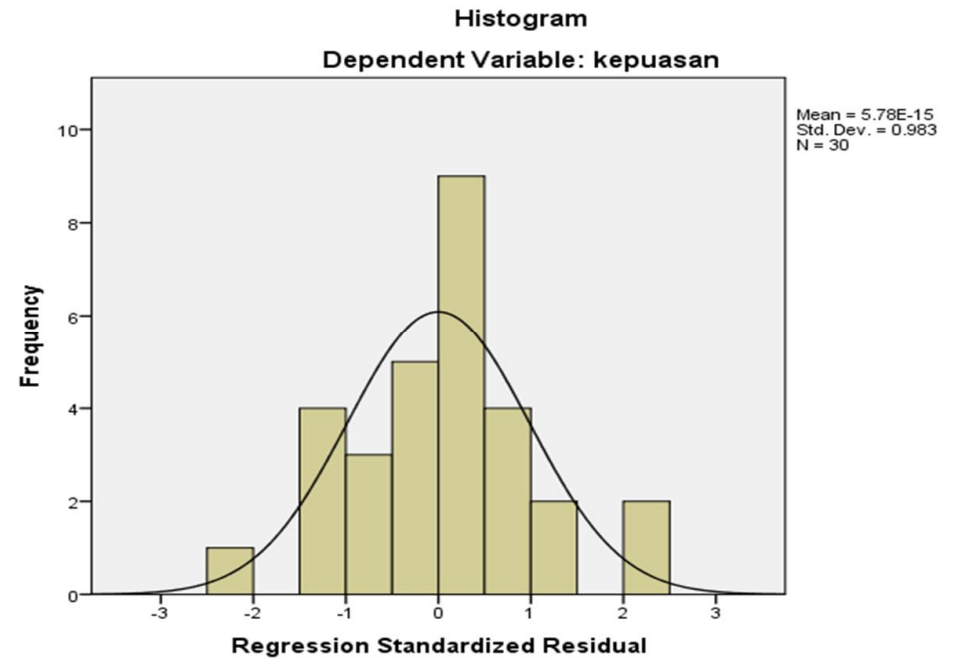

Source: Data Processing, 2016

Based on Figure 3, it can be seen that the data shows normal distribution model because the curve forms a bell. The test is performed using the normal probability plot. Figure 4 illustrates the normal probability plot used to detect whether the data used have a normal distribution or not. 


\section{Figure 4}

\section{Normal Probability Plot}

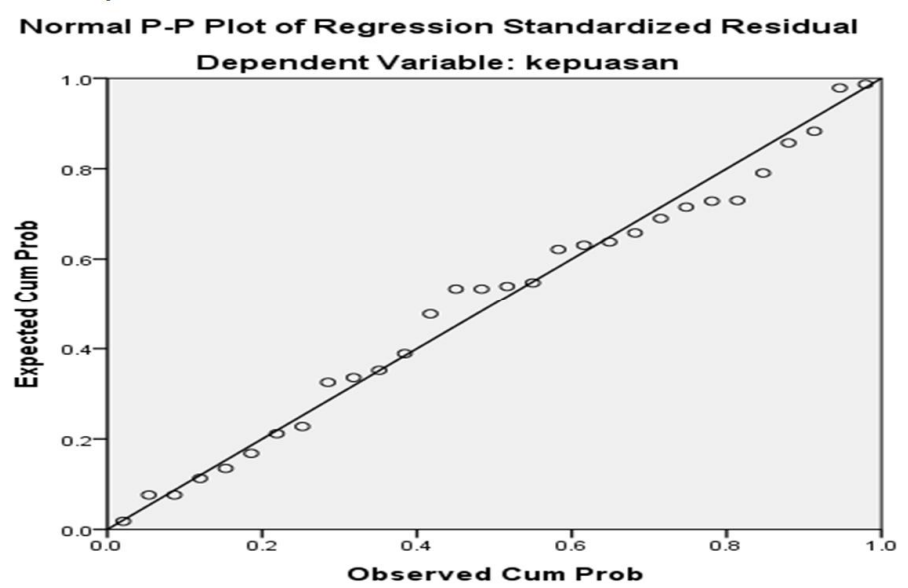

Source: Data Processing, 2016

A regression model is said to fit for use if the residual values the follows a normal distribution. Figure 4 shows normal distribution of the residual values when the distribution of the data is located around the diagonal line which is on the bottom left to the top.

\section{Effect Test Between Variables}

\section{Coefficient Values Between Variables}

Table 3 Tourism

Effect of Quality of Experience on the Satisfaction with Gastronomic

\begin{tabular}{|c|c|c|c|c|}
\hline \multicolumn{5}{|c|}{ Model Summary } \\
\hline odel & $\overline{\mathrm{R}}$ & Square $^{\mathrm{R}}$ & $\begin{array}{l}\text { Adjuste } \\
\text { d R Square }\end{array}$ & $\begin{array}{l}\text { Std. } \\
\text { Error of the } \\
\text { Estimate }\end{array}$ \\
\hline & $3^{\mathrm{a}} \quad .70$ & .60 & .000 & 1.529 \\
\hline
\end{tabular}

a. Predictors: (Constant), Quality of Experience

b. Dependent Variable: Satisfaction

Based on the coefficient test between variables, it is known that the value of R-square is 0.601 or $60.1 \%$. This indicates that the quality of experience contributes to or has an impact on satisfaction by $60.1 \%$. Meanwhile, the remaining $39.9 \%$ is the impact of other variables which are not examined. 
Simple Linear Regression Analysis Coefficients $^{\mathrm{a}}$

\begin{tabular}{|c|c|c|c|c|c|c|c|}
\hline \multirow[t]{2}{*}{ Model } & \multicolumn{2}{|c|}{$\begin{array}{l}\text { Unstandardized } \\
\text { Coefficients }\end{array}$} & \begin{tabular}{|l} 
Standar \\
dized \\
Coefficients
\end{tabular} & & $\mathrm{T}$ & g. & $\mathrm{Si}$ \\
\hline & B & Error & Beta & & & & \\
\hline (Constant) & 4.465 & .415 & & 750 & 10. & 0 & \\
\hline $\begin{array}{l}\text { Quality } \\
\text { Experience }\end{array}$ & .107 & .105 & 403 & & 1.0 & 2 & .00 \\
\hline
\end{tabular}

a. Dependent Variable: Kepuasan

The regression equation is as follows:

$\mathrm{Y}^{\prime}=\mathrm{a}+\mathrm{bX}$

$Y^{\prime}=4.465+107 \mathrm{x}$

There is an impact of the quality of food on visitor satisfaction with the Sig. $0.002<0.05$. So it can be said that Ho is rejected and Ha is accepted. The constant of 4.465 indicates that if the quality of experience is 0 (zero) and not changed, the satisfaction will be valued at 4.465 . Variable $\mathrm{X}$ (the quality of experience) has a regression coefficient of 0.107 , meaning that if the quality of experience increases by one unit, the satisfaction will increase by 0.107 units. The higher the quality of the experience, the resulting satisfaction will increase.

\section{Conclusions}

The highest response in terms of quality of experience (consisting of hedonics, peace of mind and recognition) is hedonics dimension, which is associated with affective responses such as joy, pleasure and memories of the past. Visitors feel a sense of happiness, excitement and impression after visiting Bandung gastronomic tourism. This is because the gastronomic products are known to have good quality, high innovation, and unique kind. Hedonics Indicators which get the highest score are 'impressed by the experience while enjoying the gastronomic products'. Meanwhile, in case of visitor response to satisfaction the highest score is on the expectation and reality of food quality. The quality of foods include taste, portion, innovation, presentation, texture, temperature and hygiene. Bandung gastronomic products are known to have a bad taste. In addition to be delicious, Bandung gastronomic products are served with a generous portion, texture and temperature according to the standard. Innovation and manner of presentation are considered attractive for visitors. Based on the coefficient test between variables, it is known that the value of R-square is 0.601 or $60.1 \%$. This indicates that the quality of experience contributes to or has an impact on satisfaction by $60.1 \%$. Meanwhile, the remaining $39.9 \%$ is the impact of other variables which are not examined.

\section{Recommendations}

The manager of the gastronomic tourism area in Bandung should be able to increase the satisfaction of visitors. Visitors who are satisfied will be 
customers who have a high loyalty, that they will make repeat visits to enjoy the gastronomic products in Bandung, buy a new product, will not be sensitive to the price offered, and will recommend other people to come. Satisfaction quality can be created to improve the quality of food offered, facilities that meet the needs of visitors, and comfort and safety for visitors, provide the best service, offer competitive rates, and continue to innovate both in terms of products and design services. High competition requires each attraction to be able to create a specific value that visitors cannot find anywhere else.

\section{REFERENCES}

Antón Clave, Salvador. Knafou, Rémy. (2012). Gastronomy Tourism and Globalisation. Universitat Rovirai Virgili - Tarra, Université Paris 1)

Asosiasi Pariwisata Kuliner Internasional ( ICTA)

Chang, Lan-Lan et al. (2014). Creative Tourism: A Preliminary Examination of Creative Tourists Motivation, Experience, Perceived Value and Revisit Intention. International Journal of Culture, Tourism and Hospitality Research. Vol. 8 no. 4 2014, pp. 401-419

Chen, C. F., \& Chen, F. S. 2010. Experience Quality, Perceived Value, Satisfaction and Behavioral Intentions for Heritage Tourists. Tourism Management, 31, 29-35.

Edgell. D.L, Allen M.D, Smith, G, and Swanson, J.R. (2006). Tourism Policy and Planning Yesterday, Today and Tomorrow,First Edition, USA:Elsevier.

Fandy Tjiptono, Ph. D \&Gregorius Chandra. 2011. Service, Quality, \& Satisfaction Edisi: 3. Yogyakarta: Andi.

Inskeep, Edward. (1991). Tourism Planning: An Integrated and sustainable Approach. Van Nostrand Reinhold. New York, Inc.

Kemmer, Debbie (2000), "Tradition and change in domestic roles and food preparation”, Sociology, 34, 323-333.

Kivela, J., \& Crotts, J. C. (2006). Tourism and Gastronomy: Gastronomy's Influence on How Tourists Experience a Destination. Journal of Hospitality and Tourism Research, 30(3), 354-377.

López-Guzmán \&Sandra Sánchez-Cañizares. (2011). R Gastronomy, Tourism and Destination Differentiation: A Case Study in Spain. Review of Economics \& Finance Submitted on 29/September/2011 Article ID: 1923-7529-2012$01-$

Lovelock, Christopher, and Jochen Wirtz. (2011). Service Marketing, People, Technology, Strategy. New Jersey: Prentice Hall Upper Sadle River. 
Pullphothong, Ladapha dan Sopha, Chiranut. (2012). Gastronomic Tourism In Ayutthaya, Thailand, Suan Dusit Rajabhat University.

Suwintari, I Gusti Ayu Eka. (2012). Kepuasan Wisatawan Terhadap Kualitas Pelayanan "Tourist Information Counters" Di Jalan Padma Utara Legian, Kuta. Denpasar: Universitas Udayana. Kotler, Philip and Keller, Kevin Lane. 2012. Marketing Management Fourteen Edition. Pearson Education Inc, New Jersey.

Wu, H. C., \& Li, T. (2014). A study of Experiential Quality, Perceived Value, Heritage Image, Experiential Satisfaction, and Behavioral Intentions for Heritage Tourists. Journal of Hospitality \& Tourism Research. Advance online publication. doi:10.1177/1096348014525638. 